\title{
Infliximabe no Tratamento de Uveíte Posterior Refratária em Paciente com Doença de Behçet ${ }^{(*)}$
}

\section{Infliximab Treatment for Refractory Posterior Uveitis in Behçet's Disease}

\author{
Sinara da Silva Freitas ${ }^{(1)}$, Carla da Fontoura Dionello ${ }^{(1)}$, Lucila Stange Rezende ${ }^{(2)}$, Varlei Antônio Serratto ${ }^{(2)}$, \\ Ana Carolina Beer Baumle ${ }^{(2)}$, Acir Rachid Filho ${ }^{(3)}$
}

\section{RESUMO}

Perda visual permanente, resultante de inflamação ocular recidivante, ocorre freqüentemente em pacientes com doença de Behçet, apesar de tratamento imunossupressor crônico e intensivo. Os autores relatam o caso de um paciente masculino, com 35 anos de idade, apresentando uveíte posterior, crônica e bilateral, refratária ao tratamento com corticosteróides e imunossupressores. O tratamento com infliximabe mostrou um efeito benéfico na uveíte desse paciente.

Palavras-chave: fator de necrose tumoral, doença de Behçet, uveíte posterior.

\section{INTRODUÇÃO}

A doença de Behçet é uma enfermidade inflamatória multissistêmica, crônica e de caráter recidivante, com manifestações mucocutâneas, articulares, vasculares, gastrintestinais, do sistema nervoso central e oculares. Apesar da terapia imunossupressora intensiva, a inflamação ocular recorrente, freqüente em cerca de $70 \%$ dos pacientes, pode causar perda permanente da visão em até $25 \%$ dos casos ${ }^{(1)}$.

Os autores relatam um caso de uveíte posterior, crônica e bilateral, em paciente com doença de Behçet, refratária ao tratamento convencional com corticosteróides e imunossupressores, e que teve boa resposta ao uso do infliximabe.

\begin{abstract}
Permanent vision loss resulting from relapsing ocular inflammation occurs frequently in patients with Behçet's disease, despite intensive and chronic immunosuppressive therapy. The authors report the case of a 35-year-old man with chronic bilateral posterior uveitis refractory to corticosteroids and immunosuppressive agents (methotrexate and cyclosporine) with a beneficial effect from treatment with infliximab.
\end{abstract}

Keywords: tumor necrosis factor, Behçet syndrome, posterior uveitis.

\section{RELATO DE CASO}

Paciente masculino, 35 anos de idade, portador de doença de Behçet há seis anos, em acompanhamento oftalmológico desde o início do quadro (Figura 1), foi encaminhado ao reumatologista após quatro anos, por estar apresentando uveíte posterior bilateral, crônica e progressiva, sem resposta ao tratamento com prednisona em altas doses (40 a $80 \mathrm{mg}$ / dia) associada a metotrexato $10 \mathrm{mg} / \mathrm{semana}$ e ciclosporina $400 \mathrm{mg} /$ dia. O paciente apresentava, também, aumento de peso importante (26 kg desde o início do tratamento), elevação dos níveis de pressão arterial de difícil controle e aumento progressivo da creatinina sérica (creatinina basal: $0,8 \mathrm{mg} / \mathrm{dl}$; após ciclosporina: 1,4 e 2,09 mg/dl). Ao exame

* Trabalho realizado no Serviço de Reumatologia do Hospital de Clínicas da Universidade Federal do Paraná (UFPR), Curitiba, PR, Brasil. Recebido em 17/02/2005. Aprovado, após revisão, em 20/04/2005.

1. Residente em Reumatologia do Hospital de Clínicas da UFPR.

2. Especializando(a) em Reumatologia do Hospital de Clínicas da UFPR.

3. Professor adjunto de Reumatologia do Hospital de Clínicas da UFPR.

Endereço para correspondência: Sinara da Silva Freitas. R. Ubaldino do Amaral, 360, ap. 43, CEP 80.060-190. Curitiba, PR, Brasil. Tel. (41) 262-8242; e-mail:sinarasfreitas@yahoo.com.br 
físico: PA = 200/140 mmHg; peso = $106 \mathrm{~kg}$; observavamse aftas na mucosa oral, lesões de pele acneiformes e dores articulares à palpação de joelhos e tornozelos. Uveíte refratária ao tratamento utilizado; além da disfunção renal e hipertensão arterial relacionados ao uso da ciclosporina, optou-se por suspender essa medicação e iniciar tratamento com infliximabe $300 \mathrm{mg} /$ dose (correspondendo a $3 \mathrm{mg} / \mathrm{kg}$ de peso corporal).

Logo após a primeira infusão de infliximabe, houve melhora importante da acuidade visual, com diminuição em $70 \%$ da turvação vítrea, além do desaparecimento das lesões cutâneo-mucosas e das artralgias. Infusões subseqüentes de infliximabe $300 \mathrm{mg}$ foram realizadas nas semanas 2, 6, e posteriormente a cada 8 semanas. Dois novos surtos de uveíte ocorreram, próximos às novas infusões de infliximabe (o primeiro três semanas antes da quinta infusão e o segundo quatro semanas antes da nona infusão), sendo ambos tratados com pulsoterapia de metilprednisolona $1 \mathrm{~g} /$ dia por três dias. Após o segundo surto de uveíte, a dose de infliximabe foi aumentada para $5 \mathrm{mg} / \mathrm{kg}$, totalizando $400 \mathrm{mg}$ por infusão (nessa época o paciente estava pesando $88 \mathrm{~kg}$ ), e desde então não ocorreram mais surtos de inflamação ocular.

A melhora do quadro clínico se manteve, os níveis tensionais e de creatinina retornaram ao normal e o peso do paciente diminuiu de 106 para $84 \mathrm{~kg}$. Atualmente o paciente está em uso de metotrexato $7,5 \mathrm{mg} / \mathrm{semana}$ e infusões periódicas de infliximabe $5 \mathrm{mg} / \mathrm{kg}$, manifestando apenas aftas orais e artralgias em membros inferiores próximos à infusão de infliximabe, que desaparecem logo após a sua administração (Tabela 1; Figura 2).
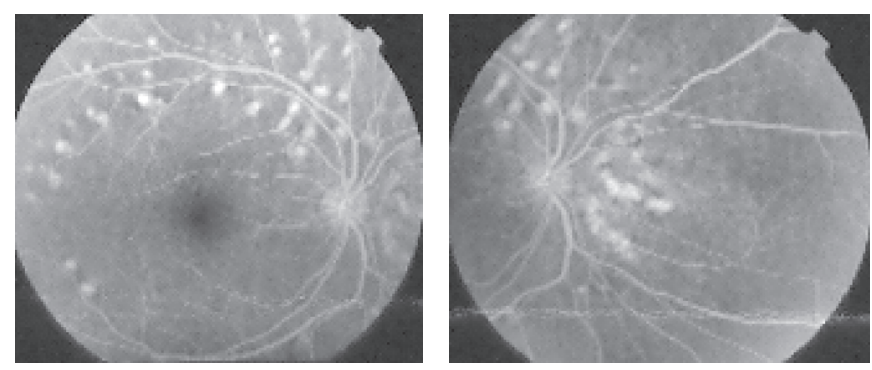

FIgURA 1 - Angiofluoresceinografia retiniana realizada em março de 1998, mostrando coroidite difusa (pontos esbranquiçados) bilateral

\section{DISCUSSÃo}

O tratamento da uveíte posterior na doença de Behçet tem sido classicamente realizado com corticosteróides associados a imunossupressores, como metotrexato, aza-
TABELA 1

INFUSÕES DE INFLIXIMABE REALIZADAS

\begin{tabular}{lccc}
\hline $\begin{array}{l}\mathbf{N}^{0} \\
\text { Infusão }\end{array}$ & Data & $\begin{array}{c}\text { Dose } \\
\text { infliximabe }(\mathrm{mg})\end{array}$ & $\begin{array}{c}\text { Dose } \\
(\mathrm{mg} / \mathrm{kg} \text { peso })\end{array}$ \\
\hline 01 & $26 / 06 / 2002$ & 300 & 3 \\
\hline 02 & $12 / 07 / 2002$ & 300 & 3 \\
\hline 03 & $11 / 08 / 2002$ & 300 & 3 \\
\hline 04 & $01 / 11 / 2002$ & 300 & 3 \\
\hline 05 & $31 / 01 / 2003$ & 300 & 3 \\
\hline 06 & $24 / 03 / 2003$ & 300 & 3 \\
\hline 07 & $21 / 05 / 2003$ & 300 & 3 \\
\hline 08 & $18 / 07 / 2003$ & 300 & 3 \\
\hline 09 & $15 / 09 / 2003$ & 400 & 5 \\
\hline 10 & $19 / 11 / 2003$ & 400 & 5 \\
\hline 11 & $22 / 01 / 2004$ & 400 & 5 \\
\hline 12 & $26 / 04 / 2004$ & 400 & 5 \\
\hline 13 & $04 / 09 / 2004$ & 400 & 5 \\
\hline 14 & $05 / 01 / 2005$ & 400 & 5 \\
\hline & & & \\
\hline
\end{tabular}
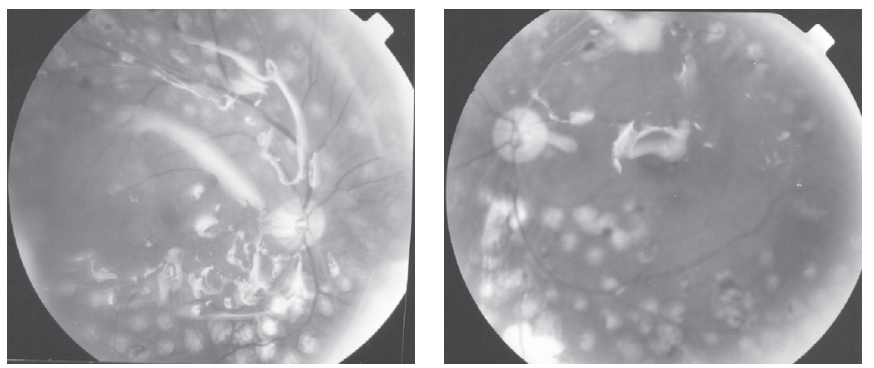

FIgURA 2 - Angiofluoresceinografia retiniana realizada em setembro de 2004, mostrando seqüelas da laserterapia (pontos branco-acinzentado), além de artefatos causados pelo óleo de silicone intra-ocular colocado após vitrectomia (imagens irregulares de cor branca), sem sinais de processo inflamatório ocular

tioprina, clorambucil, ciclofosfamida, ciclosporina e interferon- $\alpha^{(1)}$. O fator de necrose tumoral alfa (TNF- $\alpha$ ) é uma citocina inflamatória que tem um papel importante na patogênese de diversas formas de uveíte, incluindo aquela da doença de Behçet. Níveis aumentados de TNF- $\alpha$ têm sido encontrados tanto no soro quanto no humor aquoso de pacientes com uveíte ${ }^{(2,3)}$. Além disso, os níveis de TNF- $\alpha$ estão associados com atividade da inflamação ocular, havendo um aumento nos níveis séricos em pacientes com doença ativa, comparado com uma diminuição naqueles 
em remissão ${ }^{(4)}$. Baseado no papel do TNF- $\alpha$ nas uveítes, drogas anti-TNF- $\alpha$ têm sido utilizadas no tratamento de casos refratários (Tabela 2 ).

TABELA 2

ESTUDOS REALIZADOS COM INFLIXIMABE NO TRATAMENTO DE UVEítes REFRATÁRIAS EM PACIENTES COM DOENÇA DE BEHÇET

\begin{tabular}{|c|c|c|c|}
\hline Autor & Ano & $\begin{array}{c}\text { Total de } \\
\text { pacientes }(n)\end{array}$ & $\begin{array}{l}\text { Resultados } \\
\text { positivos (n) }\end{array}$ \\
\hline Goosens $^{(5)}$ & 2001 & 1 & 1 \\
\hline Sfikakis ${ }^{(6)}$ & 2001 & 5 & 5 \\
\hline Fernandez ${ }^{(7)}$ & 2001 & 1 & 1 \\
\hline Banares $^{(8)}$ & 2001 & 5 & 4 \\
\hline Triolo(o) & 2002 & 1 & 1 \\
\hline Aeberli(10) & 2002 & 1 & 1 \\
\hline Joseph ${ }^{(11)}$ & 2003 & 3 & 3 \\
\hline Gullij(12) $^{(12)}$ & 2003 & 1 & 1 \\
\hline Mansour ${ }^{(13)}$ & 2004 & 2 & 0 \\
\hline Yucel $^{(14)}$ & 2004 & 1 & 0 \\
\hline Sfikakis ${ }^{(15)}$ & 2004 & 25 & 19 \\
\hline Wechsler ${ }^{(16)}$ & 2004 & 4 & 4 \\
\hline Ohno ${ }^{(17)}$ & 2004 & 13 & 13 \\
\hline Castillo(18) & 2004 & 5 & 5 \\
\hline Giansanti $^{(19)}$ & 2004 & 1 & 1 \\
\hline
\end{tabular}

O primeiro caso de infliximabe utilizado no tratamento de uveíte em doença de Behçet foi descrito na Holanda e publicado em junho de 2001, sendo realizadas duas infusões de infliximabe $10 \mathrm{mg} / \mathrm{kg}$ de peso corporal com intervalo entre elas de um mês, ocorrendo remissão do quadro geral em um ano, não havendo menção específica com relação à evolução da uveíte ${ }^{(5)}$. No mês seguinte, foram descritos na Grécia cinco casos de pacientes com pan-uveíte em doença de Behçet que receberam infliximab $5 \mathrm{mg} / \mathrm{kg}$ em infusão única, havendo evidência de remissão da inflamação

\section{REFERÊNCIAS}

1. Kaklamani VG, Kaklamanis PG: Treatment of Behçet's disease - an update. Semin Arthritis Rheum 30: 299-312, 2001.

2. Santos-Lacomba M, Marcos Martin C, Gallardo Galera JM, et al.: Aqueous humor and serum tumor necrosis factor-alpha in clinical uveitis. Ophtalm Res 33: 251-5, 2001.

3. Bardak Y, Aridogan BC: The demonstration of serum interleukin 6-8, tumor necrosis factor-alpha, complement, and immunoglobulin ocular nas primeiras 24 horas, e supressão completa em sete dias após o tratamento em todos os pacientes ${ }^{(6)}$. Ainda em 2001 foram publicados dois outros estudos, nos quais foram realizadas infusões de infliximab $5 \mathrm{mg} / \mathrm{kg}$ nas semanas 0,2 e 6 - um, o relato de um caso com boa resposta ${ }^{(7)}$ e outro, um estudo com cinco pacientes, ocorrendo melhora em quatro dos relatados ${ }^{(8)}$.

Até o início de 2002, quando se cogitou usar infliximabe no paciente estudado neste caso, haviam sido descritos na literatura apenas 12 casos semelhantes tratados com infliximabe, ainda sem um consenso com relação à dose, ao número e ao intervalo das infusões. Desde 2002 diversos trabalhos têm sido realizados, alguns com número maior de pacientes, mostrando uma tendência à boa resposta com o uso do infliximabe ${ }^{(9-12,15-20)}$, havendo apenas descrição de três casos com resposta inadequada ${ }^{(13,14)}$. O maior estudo, realizado na Grécia e publicado em março de 2004, envolveu 25 pacientes com doença de Behçet e uveíte posterior, que receberam infusão única de infliximab $5 \mathrm{mg}$ / $\mathrm{kg}$, com controle da inflamação ocular já no primeiro dia pós-tratamento em 24 dos 25 pacientes. Quinze pacientes desse estudo que haviam tido nas últimas 32 semanas antes do infliximabe pelo menos dois surtos de inflamação ocular, foram tratados com infusões adicionais de infliximabe nas semanas 8, 16 e 24, havendo uma remissão completa em $60 \%$ dos $\operatorname{casos}^{(15)}$.

Neste estudo, o infliximabe utilizado em um paciente com uveíte posterior por doença de Behçet, refratária a corticosteróides e imunossupressores, suprimiu a inflamação ocular e possibilitou a retirada das drogas previamente usadas, desaparecendo seus efeitos colaterais. O resultado apresenta-se em conformidade com os dados publicados na literatura, e chama a atenção para o uso de uma droga que deve se utilizada com critérios - reservando-a principalmente para os casos refratários, e que tem mostrado, no geral, bons resultados. São necessários estudos controlados para avaliar melhor a eficácia do infliximabe no tratamento das uveítes, bem como estabelecer consensos sobre a dose e o tempo de tratamento a serem utilizados.

levels in Behcet's disease with ocular involvement. Ocul Immunol Inflamm 12: 53-8, 2004.

4. Misumi M, Hagiwara E, Takeno M, et al.: Cytokine production profile in patients with Behcet's Disease treated with infliximab. Cytokine 24: 210-18, 2003.

5. Goossens PH, Verburg RJ, Breedveld FC: Remission of Behçet's syndrome with tumour necrosis factor alpha blocking therapy. Ann Rheum Dis 60: 637, 2001. 
6. Sfikakis PP, Theodossiadis PG, Katsiari CG, Kaklamanis P, Markomichelakis NN: Effect of infliximab on sight-threatening panuveitis in Behçet's disease. Lancet 358:295-6, 2001.

7. Munoz-Fernandez S, Hidalgo V, Fernandez-Melon J, Schlincker A, Martin-Mola E: Effect of infliximab on threatening panuveitis in Behçet's disease. Lancet 358:1644, 2001.

8. Banares A, Abasolo L, Macarron P, Hernandez C, Jover JÁ, Fernandez B: Treatment of refractory posterior uveitis with anti-TNF-alpha (infliximab). Arthritis Rheum 44 (suppl); S120. Abstract 408, 2001.

9. Triolo G, Vadala M, Accardo-Palumbo A, et al.: Anti-tumor necrosis factor monoclonal antibody treatment for ocular Behçet's disease. Ann Rheum Dis 61: 560-1, 2002.

10. Aeberli D, Oertle S, Mauron H, Reichenbach S, Jordi B, Villiger PM: Inhibition of the TNF-pathway: use of infliximab and etanercept as remission-inducing agents in cases of therapy-resistant chronic inflammatory disorders. Swiss Med Wkly 132: 414-22, 2002.

11. Joseph A, Raj D, Dua HS, Powell PT, Lanyon PC, Powell RJ Infliximab in the treatment of refractory posterior uveitis. Ophtalmology 110: 1449-53, 2003.

12. Gulli S, Arrigo C, Bocchino L et al.: Remission of Behçet's disease with anti-tumor necrosis factor monoclonal antibody therapy: a case report. BMC Musculoskelet Disord 4: 19, 2003.
13. Mansour AM: Infliximab treatment of posterior uveitis. Ophthalmology 111: 197-8, 2004

14. Yucel AE, Kart-Koseoglu H, Akova YA, Demirhan B, Boyacioglu $\mathrm{S}$ : Failure of infliximab treatment and occurrence of erythema nodosum during therapy in two patients with Behcet's disease. Rheumatology (Oxford) 43: 394-6, 2004.

15. Sfikakis PP, Kaklamanis PH, Elezoglou A, et al.: Infliximab for recurrent, sight-threatening ocular inflammation in AdamantiadesBehcet disease. Ann Intern Med 140: 404-6, 2004.

16. Wechsler B, Sable-Fourtassou R, Bodaghi B, et al.: Infliximab in refractory uveitis due to Behcet's disease. Clin Exp Rheumatol 22 (4 Suppl 34): S14-6, 2004

17. Ohno S, Nakamura S, Hori S, et al.: Efficacy, safety, and pharmacokinetics of multiple administration of infliximab in Behcet's disease with refractory uveoretinitis. J Rheumatol 31: 1362-8, 2004.

18. Benitez-del-Castillo JM, Martinez-de-la-Casa JM, Pato-Cour, et al: Long-term treatment of refractory posterior uveitis with anti-TNF $\alpha$ (infliximab). Eye advance online publication 24 Sep 2004.

19. Giansanti F, Barbera MC, Virgili V, Emmi L, Menchini U: Infliximab for the treatment of posterior uveitis with retinal neovascularization in Behcet's disease. Eur J Ophtalmol 14: 445-8, 2004. 